\title{
DNA Vaccines Encoding Toxoplasma gondii Cathepsin C 1 Induce Protection against Toxoplasmosis in Mice
}

\author{
Yali Han', Aihua Zhou'², Gang Lu', Guanghui Zhao ${ }^{3}$, Wenchao Sha', Lin Wang ${ }^{4}$, Jingjing Guo', Jian Zhou', \\ Huaiyu Zhou', Hua Cong ${ }^{1}$, Shenyi He ${ }^{1, *}$ \\ ${ }^{1}$ Department of Parasitology, Shandong University School of Medicine, Jinan, Shandong, 250012, P. R. China; '2Department of Pediatrics, Provincial \\ Hospital Affiliated to Shandong University, Shandong University School of Medicine, Jinan, Shandong, 250021, P. R. China; ${ }^{3}$ Qilu Hospital of \\ Shandong University, Qingdao, Shandong, 266035, P. R. China; ${ }^{4}$ Department of Jinan Children's Hospital, Jinan, Shandong, 250022, P. R. China
}

\begin{abstract}
Toxoplasma gondii cathepsin C proteases (TgCPC1, 2, and 3) are important for the growth and survival of T. gondii. In the present study, B-cell and T-cell epitopes of TgCPC1 were predicted using DNAstar and the Immune Epitope Database. A TgCPC1 DNA vaccine was constructed, and its ability to induce protective immune responses against toxoplasmosis in BALB/c mice was evaluated in the presence or absence of the adjuvant a-GalCer. As results, TgCPC1 DNA vaccine with or without adjuvant a-GalCer showed higher levels of IgG and IgG2a in the serum, as well as IL-2 and IFN- $\gamma$ in the spleen compared to controls (PBS, pEGFP-C1, and a-Galcer). Upon challenge infection with tachyzoites of T. gondii (RH), pCPC1/a-Galcer immunized mice showed the longest survival among all the groups. Mice vaccinated with DNA vaccine without adjuvant ( $\mathrm{pCPC1}$ ) showed better protective immunity compared to other controls (PBS, pEGFP-C1, and a-Galcer). These results indicate that a DNA vaccine encoding TgCPC1 is a potential vaccine candidate against toxoplasmosis.
\end{abstract}

Key words: Toxoplasma gondii, DNA vaccine, CPC1, protective immunity, mouse

\section{INTRODUCTION}

Toxoplasma gondii is an obligate intracellular protozoan parasite that causes zoonotic toxoplasmosis [1,2], which poses a serious risk to animal husbandry and human health [3]. T. gondii strains are classed as virulent or weak depending on their strength of toxicity. Host infections of virulent strains can cause acute disease and even death, while infections with attenuated strains show no obvious symptoms but can lead to cyst formation in some hosts. The RH strain is representative of virulent strains $[1,2]$.

Human toxoplasmosis may cause serious clinical manifestations in the fetus and in immunocompromised individuals $[4,5]$. Infection of pregnant woman with T. gondii sometimes results in premature birth, stillbirth, miscarriage, fetal brain hydrocephalus, cerebellar malformations, and other issues [6]. The current primary strategy for the treatment of toxoplasmosis is chemical drugs, but these often cause side effects, espe-

\footnotetext{
• Received 4 March 2017, revised 14 September 2017, accepted 19 September 2017. *Corresponding author (shenyi.he@hotmail.com) (C) 2017, Korean Society for Parasitology and Tropical Medicine This is an Open Access article distributed under the terms of the Creative Commons Attribution Non-Commercial License (http://creativecommons.org/licenses/by-nc/4.0) which permits unrestricted non-commercial use, distribution, and reproduction in any medium, provided the original work is properly cited.
}

cially in the fetus, and have no effect on cysts or bradyzoites [7]. In recent decades, progress has been made in the development of vaccines against T. gondii infection, and it is hoped that DNA vaccines could be used to eliminate this parasite $[8,9]$.

Cysteine proteases are important for apicomplexan invasion, organellar biogenesis, and intracellular survival [10]. Five cathepsin proteins belonging to cysteine proteases are encoded by the $T$. gondii genome; 1 cathepsin $\mathrm{B}(\mathrm{TgCPB}), 1$ cathepsin $\mathrm{L}$ ( $\mathrm{TgCPL}$ ), and 3 cathepsin $\mathrm{C}$ (TgCPC1, 2, and 3) proteases $[10,11]$. Cathepsin C proteases are exopeptidases that are required for T. gondii tachyzoite growth and differentiation. Inhibition of these proteases leads to significant attenuation of infection by $\mathrm{T}$. gondii [10]. TgCPC1 and TgCPC2 are expressed in tachyzoites, and have been reported to occupy dense granules and the parasitophorous vacuole (PV) of tachyzoites during $T$. gondii replication. The $\mathrm{PV}$ is formed as the parasite invades the host cell. At least one of $\mathrm{TgCPC} 1$ or $\mathrm{TgCPC} 2$ is required for host cell invasion and growth, but TgCPC3 has not been detected in the tachyzoites of T. gondii $[10,11]$. TgCPC1 is expressed at high levels and is the most abundant thiol protease in T. gondii tachyzoites. Indeed, TgCPC1 mRNA levels were estimated to exceed $60 \%$ of total cathepsin mRNA levels, with $\mathrm{TgCPC} 1$ transcript levels around 20 times higher than those of 
TgCPC2 [10].

In immunology, the choice of adjuvant is a key factor in determining the effectiveness of the immune response [12]. Studies have demonstrated that $\alpha$-GalCer is a strong natural killer $\mathrm{T}$ agonist that plays a major role in the stimulation of natural killer T cells [13-15]. In some researches $\alpha$-GalCer has also been used as an adjuvant in vaccine development, and was shown to make a positive contribution [16,17].

Epitopes are chemical groups that determine antigen specificity. Predicting the epitopes is of great value for design of immunogenicity of peptides and new vaccines [18]. In the present study, we analyzed the $\mathrm{CPC} 1$ protein using a bioinformatics approach to identify potential antigenic epitopes, and constructed a TgCPC1 DNA vaccine to evaluate protective immune responses against toxoplasmosis in BALB/c mice. We show that $\mathrm{TgCPC} 1$ is a novel vaccine candidate that induces clear humoral and cellular immune responses against T. gondii infections in mice. Furthermore, $\alpha$-GalCer used as an adjuvant enhanced the immune responses.

\section{MATERIALS AND METHODS}

\section{Prediction of linear B-cell epitopes and T-cell epitopes}

TgCPC1 nucleotide (GenBank no. DQ063593.1) and amino acid sequences (GenBank no. AAZ15654.1) were obtained from GenBank. Epitopes that consist of chemical groups form the basis of protein antigenicity and determine antigen specificity $[19,20]$. We analyzed hydrophilicity plots, flexible regions, the antigenic index, and the surface probability of CPC1 and predicted linear B cell epitopes of CPC1 using DNASTAR software. Given the important role of T-cell epitopes in immunity against intracellular parasites, we used the Immune Epitope Database (IEDB; http://tools.immuneepitope.org/mhcii) online service to analyze T-cell epitopes of CPC1. The half maximal inhibitory concentration (IC50) values of peptides binding to the major histocompatibility complex (MHC) class II molecules of $\mathrm{CPC} 1$ were predicted using the online service.

\section{Animals and parasites}

Seven- to 8-week-old female BALB/c mice were obtained from Shandong University Laboratory Animal Center (Jinan, Shandong, China). Mice were bred under specific pathogenfree conditions, with food and water ad libitum. All animal experiments were approved by the Ethics Committee on Animal Experiments of the Medical School of Shandong University.
T. gondii RH strain tachyzoites were extracted from human foreskin fibroblasts $1 \mathrm{hr}$ before injection to ensure maximal freshness prior to challenge. Tachyzoites were used to produce soluble tachyzoite antigens (STAg) after digesting by 0.25 $\%$-trypsin, isolating by centrifugation, suspending in sterile PBS, sonicated for 10 min periods at $300 \mathrm{w} / \mathrm{s}$ twice, freezing and thawing at $-20^{\circ} \mathrm{C}$ (3 times) and centrifuging (10,000 rpm) for $30 \mathrm{~min}$. Collected STAg was stored at $-80^{\circ} \mathrm{C}$ before use. Total RNA was extracted from about $8 \times 10^{6}$ tachyzoites using TRIzol reagent (Life Technologies, Carlsbad, California, USA) and reverse-transcribed into CDNA with RevertAid First Strand cDNA Synthesis Kit according to the manufacturer's protocol (Thermo Scientific, Carlsbad, California, USA).

\section{Construction and preparation of plasmids}

The entire coding sequence of the T. gondii $\mathrm{CPC} 1$ gene was amplified using PCR from T. gondii CDNA with synthetic primers: forward primer, 5'-CGAGCTCAAATGGGGTCGCT GCGCAGGCGGT-3'; reverse primer, 5'-CGGGGTACCTCACATTGTTTTACTTTTCAGAGC -3' (introducing Sac I and Kpn I restriction sites, respectively, as shown by underlining). Trans TagTM High Fidelity DNA Polymerase (TransGen Biotech, Beijing, China) was used in PCR amplification.

PCR products were inserted into the pEASY-T1 Vector (TransGen Biotech), digested with the appropriate restriction enzyme, and purified from agarose gels. The $\mathrm{CPC} 1$ gene fragment was then subcloned into the eukaryotic expression plasmid pEGFP-C1 (Novagen, Billerica, Massachusetts, USA) to form pEGFP-C1-CPC1 (pCPC1). Recombinant plasmids were propagated in Escherichia coli DH5a cells and identified using PCR, restriction analysis and sequencing. Endotoxin-free plasmids were then obtained by Endofree Plasmid Mega kits (Qiagen, Hilden, Germany) following the manufacturer's instructions. The concentrations of the plasmids were assessed using A260/A280 measurement. All plasmids were diluted to $1 \mathrm{mg} /$ $\mathrm{ml}$ with sterile endotoxin-free PBS and stored at $-20^{\circ} \mathrm{C}$ until use.

\section{pCPC1 expression in human embryonic kidney (HEK) 293-T cells}

HEK 293-T cells were cultivated in Dulbecco's modified Eagle medium (DMEM) with streptomycin $(100 \mathrm{mg} / \mathrm{ml})$, penicillin $(100 \mathrm{IU} / \mathrm{ml})$, and $10 \%$ fetal bovine serum. The cells were maintained at $37^{\circ} \mathrm{C}$ in a humidified atmosphere with $5 \% \mathrm{CO}_{2}$. HEK293 cells (about 1-2 $\times 10^{5} /$ well) were plated in Costar 6-well culture plates (Sigma-Aldrich, St. Louis, Missouri, USA) 
before transfection.

HEK 293-T cells were transfected by control blank, pEGFP$\mathrm{C} 1$, and recombinant eukaryotic expression plasmids PCPC1 using lipofectamine 2000 reagent (Invitrogen, Carlsbad, California, USA) according to the manufacturer's instructions. Briefly, $7 \mu \mathrm{l} /$ well lipofectamine was mixed with plasmids (2.5 $\mu \mathrm{g} /$ well) in DMEM, and incubated at room temperature for 20 $\mathrm{min}$. The mixture was then added drop by drop to HEK 293-T cells. After $6 \mathrm{hr}$ incubation, the cell culture medium was replaced by fresh complete medium. After a further incubation of $48 \mathrm{hr}$, cells were analyzed by fluorescence microscopy with a blue laser.

\section{Immunization and challenge of mice}

Female BALB/c mice were randomly divided into 5 groups (15 mice per group). Mice were immunized intramuscularly twice in their hind legs at 2-week intervals with PBS (100 $\mu$ l), pEGFP-C1 $(100 \mu \mathrm{g})$, pCPC1 $(100 \mu \mathrm{g}), \alpha$-GalCer $(2 \mu \mathrm{g})$, or pCPC1 $(100 \mu \mathrm{g}) / \alpha$-GalCer $(2 \mu \mathrm{g})$. $\alpha$-GalCer was only injected
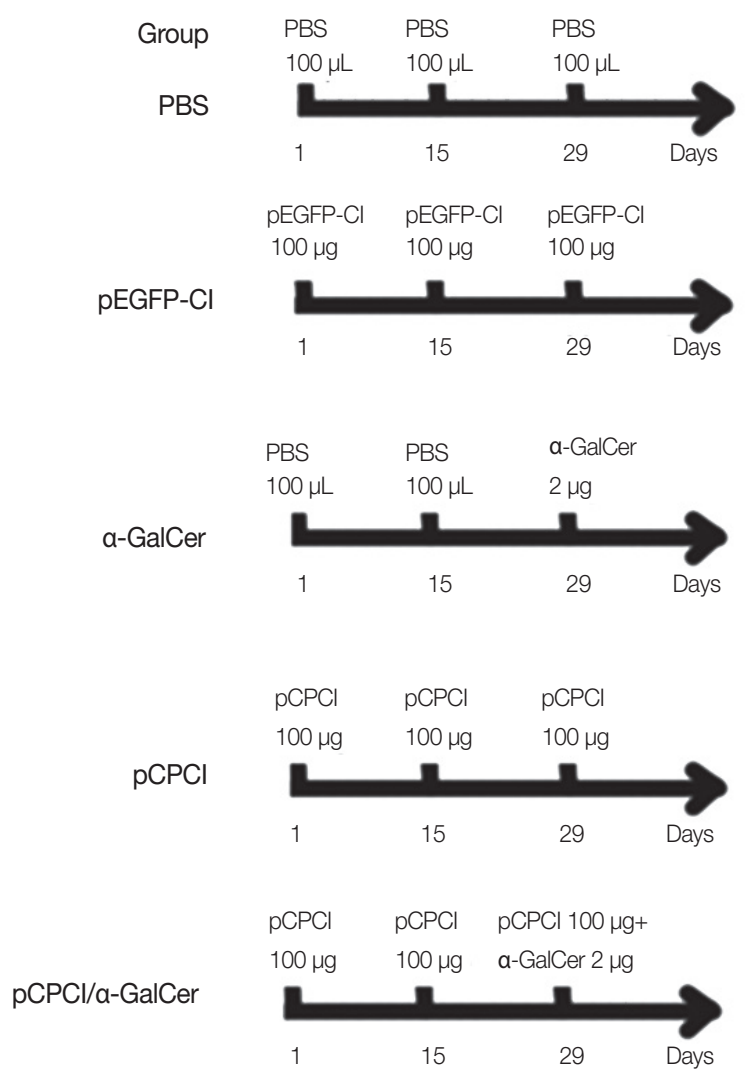

Fig. 1. Immunization schedules of BALB/c mice. All mice of 5 groups were intramuscularly injected 3 times at 2 weeks interval. a-GalCer $(2 \mu \mathrm{g})$ was diluted with $100 \mu \mathrm{l}$ PBS. at the final immunization, while other components were injected a total of 3 times [17]. Immunization schedules of BALB/c mice are shown in Fig. 1. Serum samples were collected from all mice prior to each immunization and 2 weeks after the final injection.

Two weeks after the final injection, spleens of 5 mice per group were obtained under aseptic conditions. Ten mice from each group were challenged intraperitoneally using $1 \times 10^{4}$ tachyzoites of T. gondii RH strain. The number of survival days of the mice challenged with RH strain was recorded.

\section{Antibody detection}

ELISA was used to assess antibody levels of $T$. gondii-specific serum IgG, IgG1, and IgG2a. Briefly, 96-well plates (Costar) were incubated with STAg in $50 \mathrm{mM}$ carbonate buffer (pH 9.6) at $4^{\circ} \mathrm{C}$ overnight. The treated plates were washed 3 times and sealed by $1 \%$ bovine serum albumin for $2 \mathrm{hr}$ at room temperature. The collected sera were diluted with PBS, added to the prepared plates, and incubated for $1 \mathrm{hr}$ at $37^{\circ} \mathrm{C}$. Plates were then washed and treated with horseradish peroxidase-conjugated, goat anti-mouse IgG, IgG1, or IgG2a. After washing again, the mixture was visualized by incubating with o-phenylenediamine dihydrochloride solution and $0.15 \% \mathrm{H}_{2} \mathrm{O}_{2}$. The reaction was interrupted by adding $2 \mathrm{M} \mathrm{H}_{2} \mathrm{SO}_{4}$. Lastly, ELX800 ELISA reader (BioTek, Winooski, Vermont, USA) was used to detect the optical density (OD) at $490 \mathrm{~nm}$. All samples were run 3 times. The cut-off value was calculated as mean OD+ 3SD, where the mean OD and SD were from the sera of PBSinjected mice. The serum is considered positive when the $\mathrm{OD}>$ the cut-off value [21].

\section{Cytokine detection}

Two weeks after the last injection, spleens were collected from 5 mice per group to assess the levels of cytokines. Spleen cells were obtained and cultivated in 96-well plates at $37^{\circ} \mathrm{C}$ with $5 \% \mathrm{CO}_{2}$. Cell-free supernatants were collected and used to detect IL-2 and IL-4 levels at $24 \mathrm{hr}$, IL-10 levels at $72 \mathrm{hr}$, and IFN- $\gamma$ levels at $96 \mathrm{hr}$ using commercial ELISA kits according to the manufacturer's instructions (R\&D Systems, Minneapolis, Minnesota, USA). All samples were run 3 times.

\section{Statistical analysis}

SPSS 17.0 software (IBM, Chicago, Illinois, USA) was used to carry out statistical analysis. Antibody levels and cytokine levels were analyzed by one-way analysis of variance. Mouse 
survival time was compared using the Kaplan-Meier method. Tukey's studentized range test was used for post-test comparisons. Differences were considered statistically significant if $P<0.05$.

\section{Ethics statement}

This study was approved by the Institutional Animal Care and Use Committee of Shandong University. The animals were kept and the experiments were performed in accordance with committee's criteria for the care and use of laboratory animals. All efforts were made to minimize suffering. Humane endpoints to reduce pain or distress in mice were used via euthanasia. Generally, mice were placed in a chamber and $\mathrm{CO}_{2}$ was administered at a concentration of $60 \%$ to $70 \%$ over a 5 min exposure time, after which the cervical dislocation method was sometimes used to ensure that effective euthanasia had occurred.

Table 1. IC50 values for CPC1 peptide binding to MHC class ॥ molecules obtained using the immune epitope database ${ }^{a}$

\begin{tabular}{lcc}
\hline MHC II $^{\text {allele }}{ }^{b}$ & Start-stop $^{c}$ & Percentile rank $^{d}$ \\
\hline HLA-DRB1 ${ }^{*} 01: 01$ & $17-31$ & 1.36 \\
& $441-455$ & 2.73 \\
H2-IAb & $416-430$ & 1.26 \\
& $213-227$ & 1.54 \\
H2-IAd & $7-21$ & 0.13 \\
& $719-733$ & 0.29 \\
H2-IEd & $668-682$ & 13.79 \\
& $208-222$ & 20.31 \\
\hline
\end{tabular}

${ }^{a}$ The immune epitope database (http://tools.immuneepitope.org/mhcii). The prediction was run 3 times.

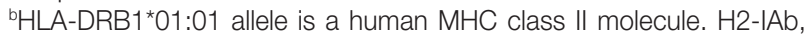
$\mathrm{H} 2$-IAd and $\mathrm{H} 2$-IEd alleles are mouse MHC class II molecules.

We chose 15 amino acids for analysis each time.

'Low percentile means high level binding; high percentile means low level binding.

\section{RESULTS}

\section{Prediction of epitopes}

Potential linear B-cell epitopes for CPC1 were identified following DNASTAR software analysis. Table 1 lists CPC1 T-cell epitopes predicted to bind strongly to MHC class II molecules, based on bioinformatics analyses.

\section{Identification and expression of restructured plasmid}

The CPC1 gene was PCR-amplified and inserted into the eukaryotic expression vector pEGFP-C1 to produce a new restructured plasmid, pCPC1. This plasmid was verified by PCR and restriction enzyme analysis. The result of restriction enzyme digestion of pCPC1 was shown in Fig. 2.

HEK 293-T cells were successfully transfected by pCPC1 and the control empty plasmid pEGFP-C1. As shown in Fig. 3,

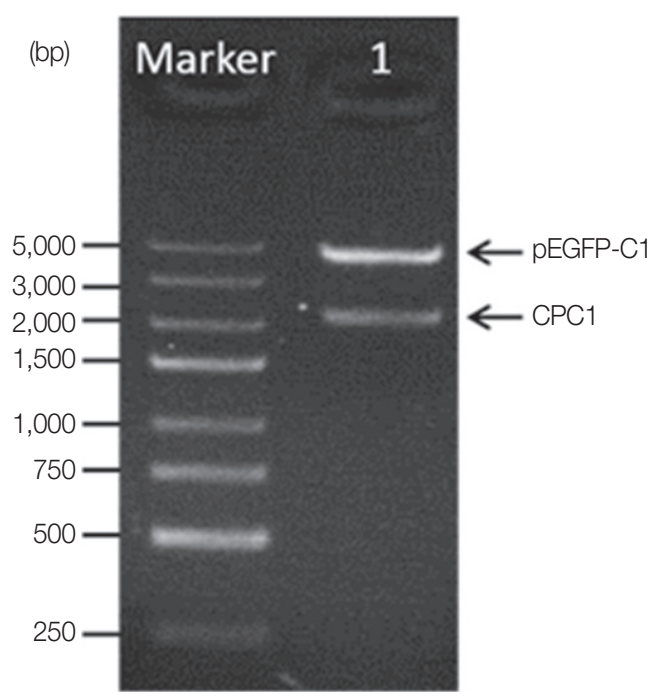

Fig. 2. Identification of pCPC1 with restriction enzyme digestion. Lane Marker, DNA marker; lane 1, pCPC1 digested with Sac I/ Kpn I.
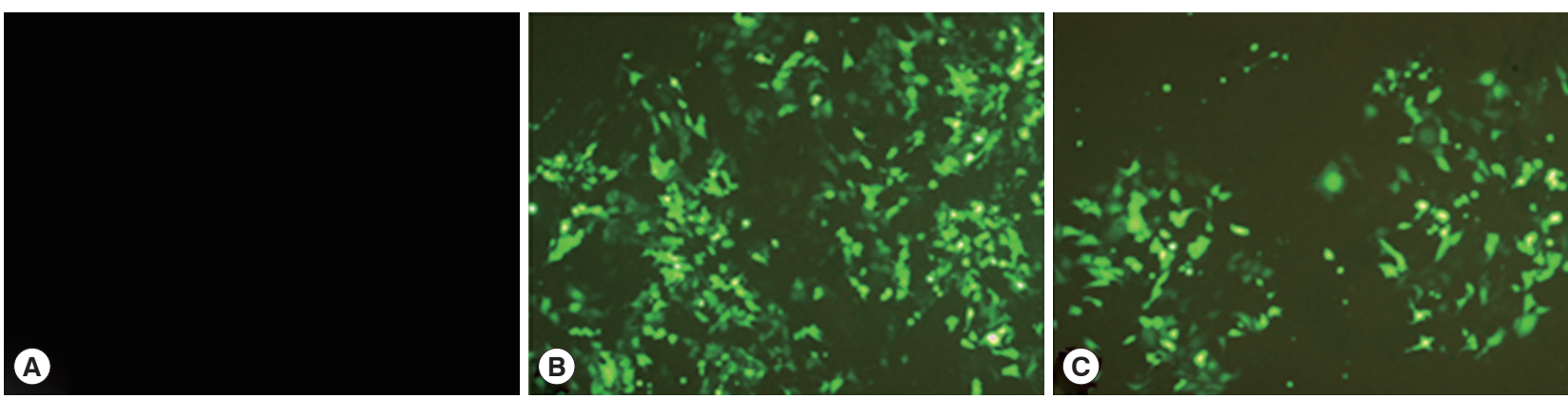

Fig. 3. The detection of the fusion protein in transfected HEK 293-T cells. (A) Cells transfected by control blank were detected under blue light. (B) Cells transfected by pEGFP-C1 were detected under blue light. (C) Cells transfected by pCPC1 were detected under blue light. 
transfected cells emitted green fluorescence when exposed to a blue laser (Fig. 3B, C), while no fluorescence was detected in control cells (Fig. 3A).

\section{Determination of antibody responses in immunized mice}

ELISA was used to assess the levels of $T$. gondii-specific IgG and IgG subclasses in the sera of mice. As shown in Fig. 4, no significant difference in IgG levels was found between the pEGFP-C1 and PBS groups, or between the $\alpha$-GalCer and PBS groups. However, significantly higher levels of IgG were detected in mice injected with $\mathrm{pCPC} 1$ and $\mathrm{pCPC} 1 / \alpha-\mathrm{GalCer}$ compared with the control groups (PBS or pEGFP-C1) $(P<0.05)$.

Two weeks after the last immunization, the levels of IgG subclasses (IgG1 and IgG2a) were assessed in all mice to verify

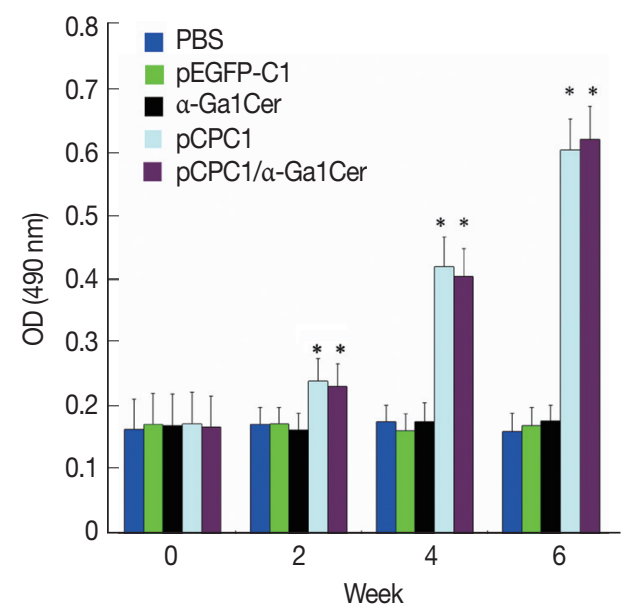

Fig. 4. Detection of specific lgG antibodies in sera of vaccinated mice by ELISA. Sera was collected prior to each immunization and 2 weeks after the final injection. All samples were performed 3 times. The results are mean of 15 mice per group and expressed as the mean of the optical density of $490 \pm S D$. ${ }^{\star} P<0.05$, as compared with PBS and pEGFP-C1. whether a Th1 and/or Th2 response was induced. As shown in Fig. 5, a predominance of IgG2a over IgG1 was detected in pCPC1-immunized mice, suggesting a shift toward a Th1 type response. We also observed a significant increase in IgG2a levels in the sera of pCPC1- and pCPC1/a-GalCer-immunized mice $(P<0.05)$. No significant differences in IgG2a levels were found between the PBS and PEGFP-C1 groups or between the PBS and $\alpha-$ GalCer groups $(P>0.05)$.

\section{Mice cytokine production}

To determine the cytokine response of mice immunized by the DNA vaccine, culture supernatants of splenocytes were obtained from mice 2 weeks after the final injection and used to detect the production of IFN- $\gamma$, IL-2, IL-4, and IL-10. As shown in Table 2, IFN- $\gamma$ levels in mice immunized with $\alpha$-GalCer, pCPC1, and pCPC1/a-GalCer were increased about 5 -fold, 10fold, and 15-fold, respectively $(P<0.05)$ compared with PBSinjected groups. Mice immunized with pCPC1/a-GalCer

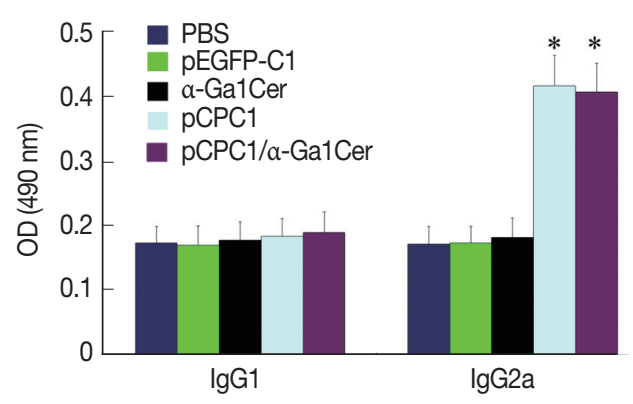

Fig. 5. Detection of lgG1 and lgG2a levels in sera of immunized mice by ELISA. Sera were collected at 2 weeks after the final injection and detected by ELISA. All samples were performed 3 times. The results are mean of 15 mice per group and expressed as the mean of the optical density of $490 \pm$ SD. ${ }^{*} P<0.05$, as compared with PBS and pEGFP-C1.

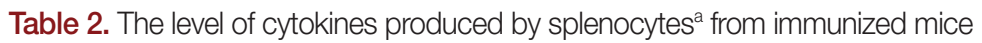

\begin{tabular}{|c|c|c|c|c|}
\hline \multirow{2}{*}{ Group } & \multicolumn{4}{|c|}{ Production of cytokine $(\mathrm{pg} / \mathrm{ml})$} \\
\hline & IFN- $\gamma$ & IL-2 & IL-4 & $\| \mathrm{L}-10$ \\
\hline PBS & $51.6 \pm 7.4$ & $32.7 \pm 5.3$ & $33.5 \pm 5.4$ & $38.7 \pm 6.6$ \\
\hline pEGFP-C1 & $55.4 \pm 7.8$ & $29.9 \pm 5.1$ & $39.0 \pm 7.2$ & $40.0 \pm 5.3$ \\
\hline a-GalCer & $311.3 \pm 35.9^{c}$ & $134.7 \pm 16.0^{c}$ & $95.4 \pm 13.6^{c}$ & $43.1 \pm 6.2$ \\
\hline pCPC1 & $586.3 \pm 54.1^{c, d}$ & $234.6 \pm 30.8^{c, d}$ & $36.2 \pm 6.1^{d}$ & $42.3 \pm 8.5$ \\
\hline
\end{tabular}

Results are presented as mean $\pm \mathrm{SD}$.

aSplenocytes from 5 mice per group 2 weeks after the final immunization.

balues for IFN- $\gamma$ are for $96 \mathrm{hr}$. Values for IL-2 and IL-4 are for $24 \mathrm{hr}$. Values for IL-10 are for 72 hr. All samples were performed 3 times.

${ }^{c} P<0.05$, as compared with PBS and pEGFP-C1.

${ }^{\mathrm{d}} P<0.05$, as compared with $a-$ GalCer.

${ }^{\mathrm{e}} \mathrm{P}<0.05$, as compared with $\mathrm{pCPC1}$. 


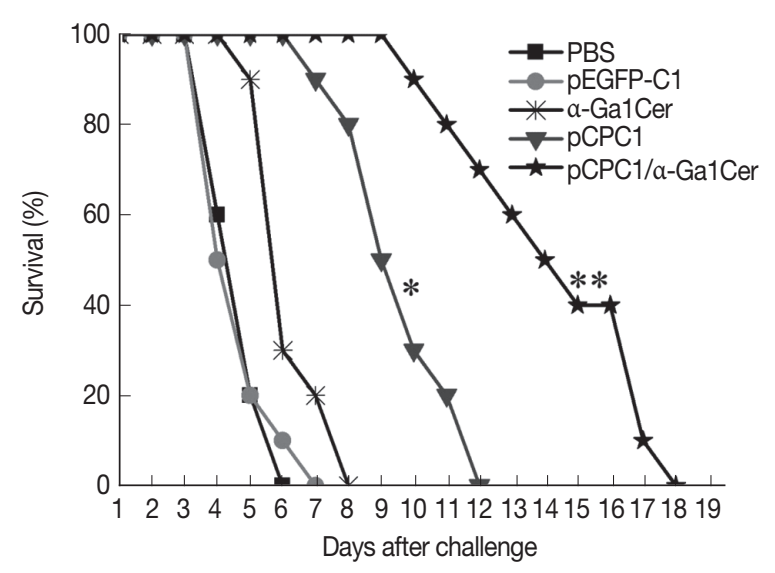

Fig. 6. Survival curves of injected BALB/c mice after T. gondii challenge infections. Ten mice per group were challenged with $1 \times 10^{4}$ tachyzoites of virulent $T$. gondii $\mathrm{RH}$ strain 2 weeks after the final immunization. Survival time was monitored daily for 18 days after challenge. ${ }^{*} P<0.05$, as compared with PBS or pEGFP-C1; ${ }^{\star \star} P<0.05$, as compared with $\mathrm{pCPC1}$.

showed the highest IFN- $\gamma$ levels of all groups $(P<0.05)$. No significant difference in IFN- $\gamma$ levels was detected between the PBS and pEGFP-C1 groups. Significantly higher levels of IL-2 were detected in mice vaccinated with $a-G a l C e r, p C P C 1$, or pCPC1/a-GalCer, compared with mice immunized with PBS or an empty plasmid $(P<0.05)$. Mice vaccinated with $a$-GalCer or pCPC1/a-GalCer had significantly higher levels of IL-4 compared with mice immunized with PBS $(P<0.05)$. However, no significant difference was found between PCPC1 and PBS groups $(P>0.05)$. IL-10 levels did not differ significantly among the 5 experimental and control groups $(P>0.05)$.

\section{Vaccine-induced protection}

To assess the level of protection induced by the DNA vaccine, 10 mice per group were challenged intraperitoneally using a lethal dose of $T$. gondii $\mathrm{RH}$ strain $\left(1 \times 10^{4}\right.$ tachyzoites). Mice were observed daily and the survival days of the challenged mice were recorded. As shown in Fig. 6, mice immunized with pCPC1 or pCPC1/a-GalCer had significantly longer survival times than control mice injected with PBS or pEGFP-C1 $(P<0.05)$. pCPC1/a-GalCer-immunized mice exhibited the longest survival time of all groups $(P<0.05)$. Although mice of the $\alpha$-GalCer group showed longer survival days compared with the PBS group, this difference was not significant $(P>0.05)$.

\section{DISCUSSION}

Bioinformatics is an interdisciplinary field that has been widely used to predict the structure and function of protein antigenic epitopes $[22,23]$. Previous studies showed that specific epitopes of proteins induced the immune response and determined the antigen specificity [24]. Epitope prediction plays an important role in T. gondii vaccine research $[25,26]$. CPC1 was reported to be important for T. gondii tachyzoite growth and differentiation. In order to predict whether TgCPC1 is suitable for vaccine, software and online services were used to predict $\mathrm{B}$ cell and T cell epitopes of CPC1. We used DNAStar software to yield several potential CPC1 B-cell epitopes, while potential T-cell epitopes were predicted using the online service IEDB. As shown in Table 1, a lower value of IC50 suggested a higher affinity and an improved $\mathrm{T}$ cell epitope. Our data analysis indicated that $\mathrm{TgCPC} 1$ could be regarded as a potential antigen and may serve as a vaccine against $T$. gondii.

In this study, $\mathrm{CPC} 1$ gene was obtained and inserted into a eukaryotic expression plasmid pEGFP-C1 following the prediction of bioinformatics. The green fluorescence was observed in recombinant plasmid transfected cells suggested that the eukaryotic expression plasmid was constructed successfully.

Previous studies have shown that cellular immunity mediated by $\mathrm{T}$ cells including $\mathrm{CD} 4^{+}$and $\mathrm{CD} 8^{+} \mathrm{T}$ lymphocytes plays a crucial role in resisting T. gondii infection $[27,28]$. According to the cytokines produced post-stimulation, $\mathrm{CD} 4{ }^{+} \mathrm{T}$ lymphocytes include 2 subtypes, Thl and Th2 cells; the former secrete IL-2 and IFN- $\gamma$, while the latter secrete IL-4, IL-5, IL-6, and IL-10 [29]. IFN- $\gamma$ plays a dominant role in controlling both tachyzoites in the acute phase of infection and bradyzoites during the chronic phase. Humoral immunity of the host is also important in resisting $T$. gondii infection, with specific IgG antibodies known to prevent $T$. gondii adhesion to host cells $[30,31]$.

A good immunization protocol was previously shown to aim for a Th1-type response rather than a Th2-type response $[32,33]$. Characteristic of this response was the large number of cytokines and high level of IgG antibodies, which are necessary for protection against $T$. gondii [34,35]. IL-4 and IL-10 cytokines were also found to limit the Th1-type immune response and to restrain IFN- $\gamma$ production $[36,37]$. In the present study, we induced a significant increase of IL-2 and especially IFN- $\gamma$ through stimulation with the DNA vaccine pEGFP-CPC1. Additionally, T. gondii-specific IgG and IgG2a anti- 
body levels were notably higher than in control groups. However, IgG1, IL-4, and IL-10 levels were similar between control and $\mathrm{PCPC} 1$ groups, indicating that $\mathrm{PCPC} 1$ mainly caused a specific Th1-type immune response. Therefore, $\mathrm{pCPC1}$ is a good potential vaccine candidate against toxoplasmosis. The immunized BALB/c mice were challenged using T. gondii tachyzoites to evaluate the protective efficacy of the DNA vaccine. The findings indicated that the mice of $\mathrm{pCPC1}$ group had significantly prolonged survival times compared with negative controls.

Single DNA vaccines often cannot provide sufficient protection against $T$. gondii infection $[38,39]$, so adjuvants may be needed to intensify the immune responses produced by the vaccines [12]. In the current study, we used the natural killer $\mathrm{T}$ cell ligand $\alpha$-GalCer to enhance the immune action of pCPC1. Stimulation of natural killer T cells by $\alpha$-GalCer was previously shown to cause the production of IL-2, IL-4, and IFN- $\gamma$, and the activation of NK, CD4(+), and CD8(+) T cells $[16,40,41]$. In line with this, we detected higher levels of IFN- $\gamma$, IL-2, and IL-4 in mice vaccinated with $\alpha$-GalCer compared with control mice. Moreover, the highest levels of IFN- $\gamma$ and IL- 2 were detected and the longest survival time was recorded in mice vaccinated with $\mathrm{pCPC} 1 / \mathrm{a}$-GalCer among all groups. These results suggest that the adjuvant $\alpha$-GalCer enhances the efficacy of the DNA vaccine $\mathrm{pCPC1}$ associating with immune responses against $T$. gondii.

In conclusion, the DNA vaccine CPC1 elicited marked immune responses against $T$. gondii, which were enhanced by the adjuvant $\alpha$-GalCer. This indicates that the vaccine CPC1 with combined adjuvant could be a new candidate for further vaccine development against toxoplasmosis.

\section{ACKNOWLEDGMENTS}

This work was supported in part by grants from the National Natural Science Foundation of China (grant nos. 81071373 and 81271857), the State Key Laboratory of Veterinary Etiological Biology (grant no. SKLVEB2011KFKT005) and the Shandong Provincial Natural Science Foundation (grant no. ZR2016HM74).

\section{CONFLICT OF INTEREST}

The authors declare that they have no competing interests.

\section{REFERENCES}

1. Dubey JP. The history of Toxoplasma gondii--the first 100 years. J Eukaryot Microbiol 2008; 55: 467-475.

2. Montoya JG, Liesenfeld O. Toxoplasmosis. Lancet 2004; 363 : 1965-1976.

3. Cenci-Goga BT, Rossitto PV, Sechi P, McCrindle CM, Cullor JS. Toxoplasma in animals, food, and humans: an old parasite of new concern. Foodborne Pathog Dis 2011; 8: 751-762.

4. McLeod R, Kieffer F, Sautter M, Hosten T, Pelloux H. Why prevent, diagnose and treat congenital toxoplasmosis? Mem Inst Oswaldo Cruz 2009; 104: 320-344.

5. Weiss LM, Dubey JP. Toxoplasmosis: a history of clinical observations. Int J Parasitol 2009; 39: 895-901.

6. Andrade GM, Vasconcelos-Santos DV, Carellos EV, Romanelli RM, Vitor RW, Carneiro AC, Januario JN. Congenital toxoplasmosis from a chronically infected woman with reactivation of retinochoroiditis during pregnancy. J Pediatr (Rio J) 2010; 86: 85-88.

7. Meng M, Zhou A, Lu G, Wang L, Zhao G, Han Y, Zhou H, Cong H, Zhao Q, Zhu XQ, He S. DNA prime and peptide boost immunization protocol encoding the Toxoplasma gondii GRA4 induces strong protective immunity in BALB/c mice. BMC Infect Dis 2013; 13: 494.

8. Jongert E, Roberts CW, Gargano N, Förster-Waldl E, Petersen E. Vaccines against Toxoplasma gondii: challenges and opportunities. Mem Inst Oswaldo Cruz 2009; 104: 252-266.

9. Hiszczyńska-Sawicka E, Holec-Gasior L, Kur J. DNA vaccines and recombinant antigens in prevention of Toxoplasma gondii infections-current status of the studies. Wiad Parazytol 2009; 55: 125139.

10. Que X, Engel JC, Ferguson D, Wunderlich A, Tomavo S, Reed SL. Cathepsin Cs are key for the intracellular survival of the protozoan parasite, Toxoplasma gondii. J Biol Chem 2007; 282: 49945003.

11. Dou Z, Carruthers VB. Cathepsin proteases in Toxoplasma gondii. Adv Exp Med Biol 2011; 712: 49-61.

12. Saade F, Petrovsky N. Technologies for enhanced efficacy of DNA vaccines. Expert Rev Vaccines 2012; 11: 189-209.

13. Kakimi K, Guidotti LG, Koezuka Y, Chisari FV. Natural killer T cell activation inhibits hepatitis B virus replication in vivo. J Exp Med 2000; 192: 921-930.

14. Kamijuku H, Nagata $Y$, Jiang $X$, Ichinohe T, Tashiro T, Mori $K$, Taniguchi M, Hase K, Ohno H, Shimaoka T, Yonehara S, Odagiri T, Tashiro M, Sata T, Hasegawa H, Seino KI. Mechanism of NKT cell activation by intranasal coadministration of $\alpha$-galactosylceramide, which can induce cross-protection against influenza viruses. $\mathrm{Mu}$ cosal Immunol 2008; 1: 208-218.

15. Dhodapkar MV, Richter J. Harnessing natural killer T (NKT) cells in human myeloma: progress and challenges. Clin Immunol 2011; 140: 160-166.

16. Gonzalez-Aseguinolaza G, Van Kaer L, Bergmann CC, Wilson JM, Schmieg J, Kronenberg M, Nakayama T, Taniguchi M, Koe- 
zuka Y, Tsuji M. Natural killer T cell ligand a-galactosylceramide enhances protective immunity induced by malaria vaccines. J Exp Med 2002; 195: 617-624.

17. Lu G, Zhou A, Meng M, Wang L, Han Y, Guo J, Zhou H, Cong H, Zhao Q, Zhu XQ, He S. a-Galactosylceramide enhances protective immunity induced by DNA vaccine of the SAG5D gene of Toxoplasma gondii. BMC Infect Dis 2014; 14: 3862.

18. Bai Y, He S, Zhao G, Chen L, Shi N, Zhou H, Cong H, Zhao Q, Zhu XQ. Toxoplasma gondii: bioinformatics analysis, cloning and expression of a novel protein TgIMP1. Exp Parasitol 2012; 132: 458-464.

19. Van Regenmortel MH. What is a B-cell epitope? Methods Mol Biol 2009; 524: 3-20.

20. Gao J, Faraggi E, Zhou Y, Ruan J, Kurgan L. BEST: improved prediction of B-cell epitopes from antigen sequences. PLoS One 2012; 7: e40104.

21. Cong H, Gu QM, Yin HE, Wang JW, Zhao QL, Zhou HY, Li Y, Zhang JQ. Multi-epitope DNA vaccine linked to the A2/B subunit of cholera toxin protect mice against Toxoplasma gondii. Vaccine 2008; 26: 3913-3921.

22. Romano P, Giugno R, Pulvirenti A. Tools and collaborative environments for bioinformatics research. Brief Bioinform 2011; 12: 549-561.

23. Reilly EC, Thompson EA, Aspeslagh S, Wands JR, Elewaut D, Brossay L. Activated iNKT cells promote memory CD8+ T cell differentiation during viral infection. PLoS One 2012; 7: e37991.

24. Wang Y, Wang G, Cai J, Yin H. Review on the identification and role of Toxoplasma gondii antigenic epitopes. Parasitol Res 2016; 115: 459-468.

25. Martin DM, Berriman M, Barton GJ. GOtcha: a new method for prediction of protein function assessed by the annotation of seven genomes. BMC Bioinformatics 2004; 5: 178.

26. Wang Y, Wang G, Ou J, Yin H, Zhang D. Analyzing and identifying novel B cell epitopes within Toxoplasma gondii GRA4. Parasit Vectors 2014; 7: 474.

27. Filisetti D, Candolfi E. Immune response to Toxoplasma gondii. Ann Ist Super Sanita 2004; 40: 71-80.

28. El-Kady IM. T-cell immunity in human chronic toxoplasmosis. J Egypt Soc Parasitol 2011; 41: 17-28.

29. Oldenhove G, Bouladoux N, Wohlfert EA, Hall JA, Chou D, Dos Santos L, O'Brien S, Blank R, Lamb E, Natarajan S, Kastenmayer R, Hunter C, Grigg ME, Belkaid Y. Decrease of Foxp3+ Treg cell number and acquisition of effector cell phenotype during lethal infection. Immunity 2009; 31: 772-786.

30. Sayles PC, Gibson GW, Johnson LL. B cells are essential for vaccination-induced resistance to virulent Toxoplasma gondii. Infect Immun 2000; 68: 1026-1033.

31. Kang H, Remington JS, Suzuki Y. Decreased resistance of B celldeficient mice to infection with Toxoplasma gondii despite unimpaired expression of IFN- $\gamma$, TNF- $\alpha$, and inducible nitric oxide synthase. J Immunol 2000; 164: 2629-2634.

32. Liu KY, Zhang DB, Wei QK, Li J, Li GP, Yu JZ. Biological role of surface Toxoplasma gondii antigen in development of vaccine. World J Gastroenterol 2006; 12: 2363-2368.

33. Zheng B, Lu S, Tong Q, Kong Q, Lou D. The virulence-related rhoptry protein 5 (ROP5) of Toxoplasma gondii is a novel vaccine candidate against toxoplasmosis in mice. Vaccine 2013; 31: 4578-4584.

34. Gazzinelli RT, Hieny S, Wynn TA, Wolf S, Sher A. Interleukin 12 is required for the T-lymphocyte-independent induction of interferon gamma by an intracellular parasite and induces resistance in T-cell-deficient hosts. Proc Natl Acad Sci U S A 1993; 90: 6115-6119.

35. Machado AV, Caetano BC, Barbosa RP, Salgado AP, Rabelo RH, Garcia CC, Bruna-Romero O, Escriou N, Gazzinelli RT. Prime and boost immunization with influenza and adenovirus encoding the Toxoplasma gondii surface antigen 2 (SAG2) induces strong protective immunity. Vaccine 2010; 28: 3247-3256.

36. Gazzinelli RT, Wysocka M, Hieny S, Scharton-Kersten T, Cheever A, Kühn R, Müller W, Trinchieri G, Sher A. In the absence of endogenous IL-10, mice acutely infected with Toxoplasma gondii succumb to a lethal immune response dependent on CD4+ T cells and accompanied by overproduction of IL-12, IFN- $\gamma$ and TNF- $\gamma$. J Immunol 1996; 157: 798-805.

37. Dawson HD, Beshah E, Nishi S, Solano-Aguilar G, Morimoto M, Zhao A, Madden KB, Ledbetter TK, Dubey JP, Shea-Donohue T, Lunney JK, Urban JF Jr. Localized multigene expression patterns support an evolving Th1/Th2-like paradigm in response to infections with Toxoplasma gondii and Ascaris suum. Infect Immun 2005; 73: 1116-1128.

38. Desolme B, Mévélec MN, Buzoni-Gatel D, Bout D. Induction of protective immunity against toxoplasmosis in mice by DNA immunization with a plasmid encoding Toxoplasma gondii GRA4 gene. Vaccine 2000; 18: 2512-2521.

39. Zhao G, Zhou A, Lu G, Meng M, Sun M, Bai Y, Han Y, Wang L, Zhou H, Cong H, Zhao Q, Zhu XQ, He S. Identification and characterization of Toxoplasma gondii aspartic protease 1 as a novel vaccine candidate against toxoplasmosis. Parasit Vectors 2013; 6: 175.

40. Kitamura H, Iwakabe K, Yahata T, Nishimura S, Ohta A, Ohmi Y, Sato M, Takeda K, Okumura K, Van Kaer L, Kawano T, Taniguchi M, Nishimura T. The natural killer T (NKT) cell ligand a-galactosylceramide demonstrates its immunopotentiating effect by inducing interleukin (IL)-12 production by dendritic cells and IL-12 receptor expression on NKT cells. J Exp Med 1999; 189: 1121-1128.

41. Ichikawa T, Negishi Y, Shimizu M, Takeshita T, Takahashi H. a-Galactosylceramide-activated murine NK1.1(+) invariant-NKT cells in the myometrium induce miscarriages in mice. Eur J Immunol 2016; 46: 1867-1877. 